\title{
Full-scale vibrating pervaporation membrane unit: VOC removal from water and surfactant solutions
}

\author{
Leland M. Vane*, Franklin R. Alvarez \\ National Risk Management Research Laboratory, United States Environmental Protection Agency, Cincinnati, OH 45268, USA
}

Received 29 May 2001; received in revised form 8 November 2001; accepted 14 November 2001

\begin{abstract}
A commercial-scale vibrating membrane system was evaluated for the separation of volatile organic compounds (VOCs) from aqueous solutions by pervaporation. Experiments with surrogate solutions of up to five VOCs in the presence and absence of a surfactant were performed to compare performance of the full-scale vibrating system with that previously observed at the laboratory-scale as well as the performance of the same full-scale system during a recent field demonstration project. The primary process variables studied were amplitude of vibration, temperature, liquid flow rate, and permeate pressure. Data were obtained with two types of silicone rubber membranes-a thick $(254 \mu \mathrm{m})$ fiberglass reinforced silicone membrane and a more typical pervaporation membrane consisting of a $10 \mu \mathrm{m}$ silicone layer on a microporous support. The full-scale vibrating system delivered mass transfer coefficients comparable to those observed at the laboratory-scale and, under certain conditions, were comparable to those obtained with spiral wound pervaporation modules. (C) 2002 Elsevier Science B.V. All rights reserved.
\end{abstract}

Keywords: Concentration polarization; Module design; Pervaporation; Water treatment; Volatile organic compounds

\section{Introduction}

The dominance of the liquid boundary layer mass transfer resistance on the removal of volatile organic compounds (VOCs) from water by pervaporation is well documented in the literature [1-5]. The result of this phenomenon, often referred to as concentration polarization, is that the VOC mass transfer efficiency and $\mathrm{VOC} /$ water selectivity are greatly reduced relative to that afforded by the membrane alone. To further complicate matters, when pervaporation has been applied to the removal of VOCs from actual groundwater, fouling of the membrane modules has been observed [6-9]. While typical membrane fouling

\footnotetext{
* Corresponding author. Tel.: +1-513-569-7799; fax: +1-513-569-7677.

E-mail address: vane.leland@epa.gov (L.M. Vane).
}

involves the blinding of the membrane surface, fouling in pervaporation systems treating groundwater has generally involved the blockage of liquid flow paths in the modules by oils and precipitant particles. In an effort to address both module fouling and concentration polarization issues, a research project was initiated in 1997 at the United States Environmental Protection Agency's National Risk Management Research Laboratory (EPA-NRMRL) to evaluate a vibrating membrane system for pervaporation separations. Initial laboratory-scale experiments demonstrated a significant reduction in concentration polarization due to membrane vibrations with VOC mass transfer coefficients approaching those obtained with traditional spiral wound modules [10]. The unobstructed flow path of this system (i.e. no flow spacers or turbulence enhancers) combined with the shearing force created by vibration of the mem- 
brane made particulate or oil fouling of the module unlikely.

Beginning in 1996, EPA-NRMRL participated in a Department of Defense project to demonstrate the use of a surfactant-based fluid to remediate soils contaminated with chlorinated solvents. This approach is often referred to as "surfactant enhanced aquifer remediation (SEAR)". As part of this project, a field demonstration was performed in the spring of 1999 at United States Marine Corps Base Camp Lejeune in Jacksonville, North Carolina. EPA-NRMRL was responsible for designing, building, and field operating a pervaporation unit to remove the chlorinated solvent, tetrachloroethylene (PCE), from the remediation fluid recovered in extraction wells. The surfactant in the decontaminated remediation fluid was then reconcentrated using micellar enhanced ultrafiltration. The ultrafiltration system was designed, constructed, and operated by researchers from the University of Oklahoma. Pervaporation was selected for this application because the non-porous membrane would alleviate foaming problems often encountered when vapor-liquid mass transfer processes such as air stripping or vacuum stripping are employed to remove VOCs from surfactant solutions. Only the VOC and a portion of the water in the solution would be removed by pervaporation, leaving behind all of the surfactant in the liquid phase. Two types of pervaporation systems were employed during the demonstration. Because of the promising laboratory-scale results, one of the field systems was a vibrating pervaporation unit. The other pervaporation system consisted of hollow fiber membrane modules. The design and field performance of the pervaporation system during this field demonstration are detailed elsewhere [11].

Due to production complications and the field activity schedule, the vibrating pervaporation field unit was unavailable for pre-field testing. In order to better understand the performance characteristics of the system, a series of post-field experiments were performed with the same system used in the field. As detailed later in this paper, the field unit was constructed with a silicone rubber conveyor belt material as the pervaporation membrane. Approximately 1 year after completing the field project, a second vibrating pervaporation module, constructed with a more traditional pervaporation silicone membrane, was evaluated. The results of post-field experiments with the field unit and with the subsequent module are reported herein. Observed performance characteristics are compared to those observed during the field demonstration and with a laboratory-scale vibrating module as well as those observed with traditional spiral wound pervaporation modules.

\section{Experimental}

Reagents (all chemicals were used as received): laboratory solvents, process VOCs, and other reagents were purchased from Sigma-Aldrich. VOCs included toluene (CAS\# 108-88-3), trichloroethylene (TCE, CAS\# 79-01-6), PCE (CAS\# 127-18-4), 1,1,1-trichloroethane (1,1,1-TCA, CAS\# 71-55-6), $p$-xylene (CAS\# 106-42-3), and methyl $t$-butyl ether (MTBE, CAS\# 1634-04-4). The surfactant used for a subset of the experiments was the same as that used during the Camp Lejeune field demonstration, sodium $\left(\mathrm{C}_{14} \text { or } 15 \text { branched alcohol) (propylene oxide }\right)_{4}$ ether sulfate with a molecular weight of approximately $553 \mathrm{~g} / \mathrm{mol}$. This anionic surfactant, produced by CONDEA Vista, is referred to as Alfoterra145 4PO ether sulfate (Alfoterra145). In previous reports, this surfactant has also been referred to as Isalchem145 4PO ether sulfate (IC145). As delivered, the surfactant contained 34.5 wt. $\%$ active surfactant. The manufacturer reported a critical micelle concentration of $0.0087 \mathrm{~g} / \mathrm{l}$ for this surfactant in the presence of $0.01 \mathrm{M}$ sodium sulfate.

\subsection{Pilot-scale experimental system}

The process schematic diagram for the pilot-scale unit is presented in Fig. 1. A 1000 gal epoxy-lined fiberglass reinforced plastic tank (Raven Industries Model DF354) served as the feed tank for the system. The contents of this tank could be mixed using a $20 \mathrm{gpm}$ recirculation loop which was separate from the feed stream. The centrifugal feed pump (Eastern Centrichem Pump Model ET7M-1725), drew fluid from the bottom of the feed tank at the desired flow rate and passed it through a $40 \mu \mathrm{m}$ cartridge filter. The feed solution was pumped through a heat exchanger (Vicarb Inc.), an electric heater (Gaumer Co., Model C4F6N 40H4-RK-ER-X, $30 \mathrm{~kW}$ heater with Fenwal Series 920 Model 923 digital indicating controller 


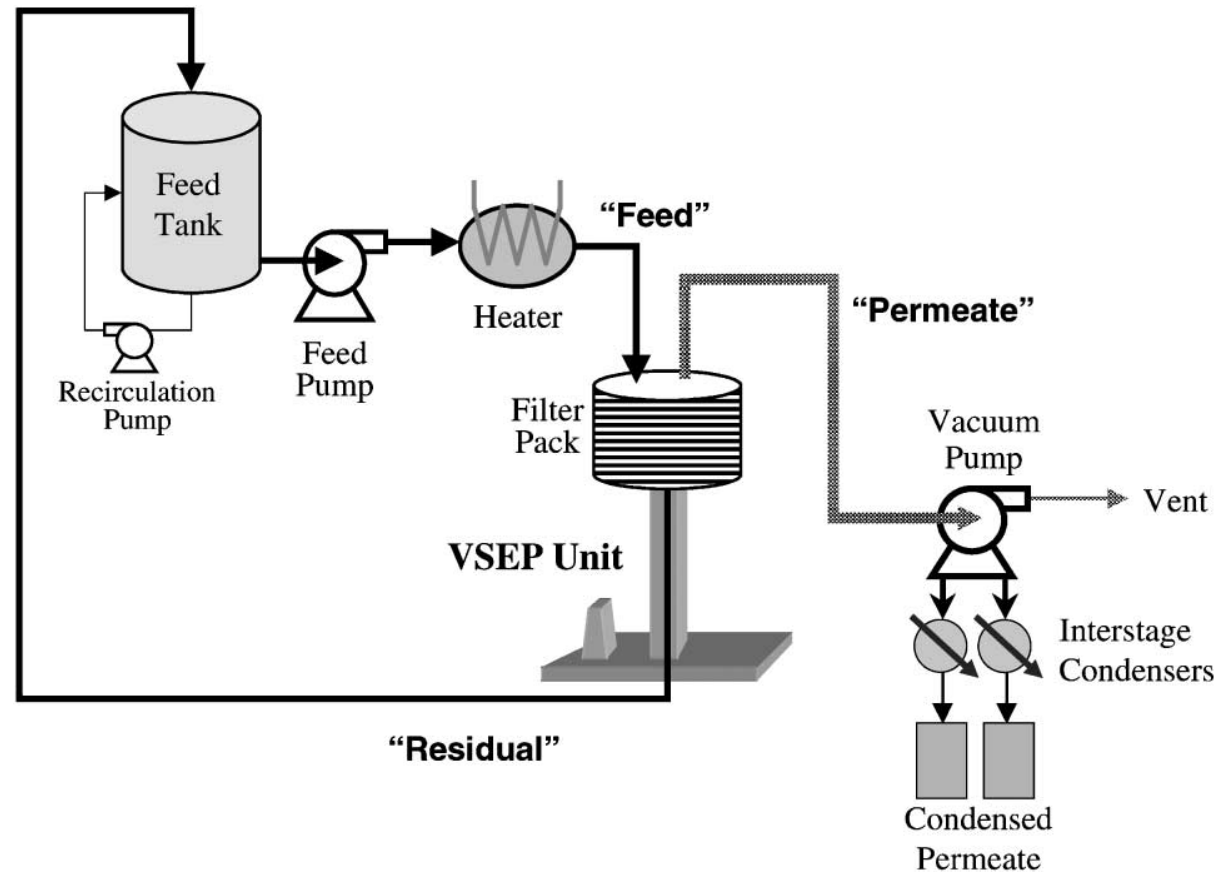

Fig. 1. Schematic diagram of the EPA-NRMRL pilot-scale pervaporation system with the vibrating membrane unit installed.

with Newport Model 82 alarm unit), and a two-stage bag filtration system (Strainrite Bag Filter, Harrington Corro-Flo) with the finest filter being either 1 or $5 \mu \mathrm{m}$ nominal particle retention. In the heat exchanger, the influent stream was preheated using heat recovered from the pervaporation residual stream.

The heated and filtered feed solution was sent to the pervaporation module(s). The treated solution (residual) then flowed through the recovery heat exchanger and back to the feed tank. Vacuum was supplied to the pervaporation membrane module(s) by a multi-stage dry chemical vacuum pump with integrated vapor compression and condensation (Stokes Vacuum, CD-75 Dry Pump, $75 \mathrm{cfm}$ nominal, $5 \mathrm{hp}$ ). A recirculating chiller (Icewagon Industries, Model DE5AC, 5 tonnes capacity) provided coolant at $1{ }^{\circ} \mathrm{C}$ to condense the permeate. The two-phase (water and organic) permeate condensate was drawn from the reservoirs by hand.

For this system, one or more types of pervaporation modules were evaluated in series - a vibrating module operated alone or followed by a set of either hollow fiber modules or spiral wound modules. The vibrating unit (vibrational shear enhanced process (VSEP)) consisted of one membrane module, a $15 \mathrm{in}$. tall module, the smallest industrial scale model produced by the vendor, New Logic International (Emeryville, CA). A picture of the EPA-NRMRL VSEP unit is provided in Fig. 2. In simplified terms, the VSEP module is a cylindrical plate and frame module mounted on top of a torsion spring. A cutaway side view drawing of the module is shown in Fig. 3a. Liquid flows across the face of each tray and flows from one tray to another via two grommeted holes in each tray. Diverter trays with one covered grommet hole cause liquid to flow across several trays in parallel, as shown in Fig. 3a. Vacuum is supplied to each tray via a central $6.125 \mathrm{in}$. diameter cylindrical cavity in the module. O-ring seals separate the trays and isolate the feed zone from the permeate zone. Vibration of a seismic mass at the base of the torsion spring causes a harmonic rotational vibration in the membrane module as pictured in Fig. 3b. The vibration frequency determines the amplitude of vibration (measured at the outer perimeter of the module). Vibration amplitudes of $0,0.25,0.5,0.75$ and 1 in. were studied corresponding to vibration frequencies 


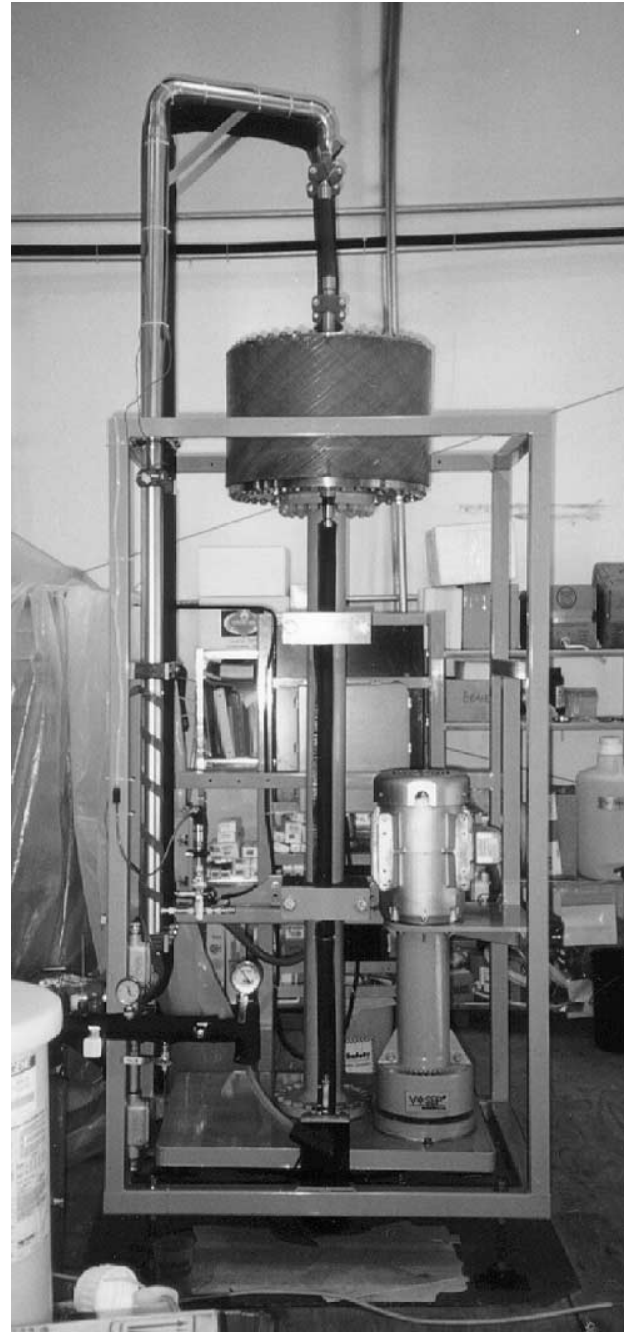

Fig. 2. VSEP pervaporation unit equipped with the CF1010 module (here, the module is $15 \mathrm{in}$. in height). Picture taken during field demonstration at United States Marine Corps Base Camp Lejeune in spring 1999.

of 0 (no measurable amplitude up to about $46 \mathrm{~Hz}$ ), $47.5,49.6,50$ and $50.2 \mathrm{~Hz}$, respectively. Thus, the entire range of amplitudes were achieved with less than a $10 \%$ change in frequency indicating that small frequency changes near the mass-spring-mass harmonic frequency result in large amplitude changes. Due to the small frequency range, the effect of vibration on pervaporation performance is best studied using vibration amplitude as the independent variable. The shearing force, thus, generated greatly reduces the likelihood of fouling and concomitantly reduces the liquid phase resistance to VOC mass transfer.

Two VSEP modules were evaluated. Both contained 38 membrane trays yielding a total membrane area of approximately $10 \mathrm{~m}^{2}$. Each tray consisted of a thin stainless steel support disk with thirteen layers of a melt spun polypropylene permeate drainage cloth (Typar ${ }^{\circledR}$ T-135) and a membrane attached to each face. Permeate flux is highest at the inner diameter of the tray because the cross-sectional permeate flow area decreases with decreasing radial position and because permeate flow from the entire tray membrane area is flowing through that cross-section. In addition, the center O-ring and O-ring retainer compress the permeate drainage cloth at the inner tray diameter. Thus, more layers of this permeate drainage cloth are required at the inner diameter than at the outer diameter. However, fewer layers of drainage cloth result in a denser tray packing (i.e. more membrane area per module). In order to maximize tray packing density while maintaining sufficient permeate flow area at the inner diameter, a tapered drainage cloth pattern was employed in which each drainage cloth had the same inner diameter, but a variety of outer diameters was employed. As a result, thirteen layers of drainage cloth were present at the inner diameter of the tray, but only three of layers extended to the outer diameter of the membrane. The height of the liquid flow channel between each tray was about 0.24 in. $(6 \mathrm{~mm})$. The first module evaluated was the same as that used in the Camp Lejeune field demonstration mentioned earlier [11]. In this first module, to be designated as the coated fabric 1010 (CF1010) module, the membrane was a silicone rubber conveyor belt material (COHRlastic ${ }^{\circledR}$ CF1010, fiberglass fabric coated on both sides with silicone rubber, total thickness of $254 \mu \mathrm{m}$, Furon Corporation). The CF1010 module contained five diverter trays arranged to give a tapered flow pattern with 12 trays in parallel at the top but only four trays in parallel at the bottom of the module. This tapered pattern, 12-10-7-5-4, is characteristic of patterns employed in VSEP filtration modules in which the water content of the retentate decreases (solids increase) as it flows through the module, thus, maintaining a constant cross-flow velocity. However, due to the low transmembrane flux in pervaporation, such a tapered pattern results in an increasing cross-flow velocity as the fluid travels through the module. 

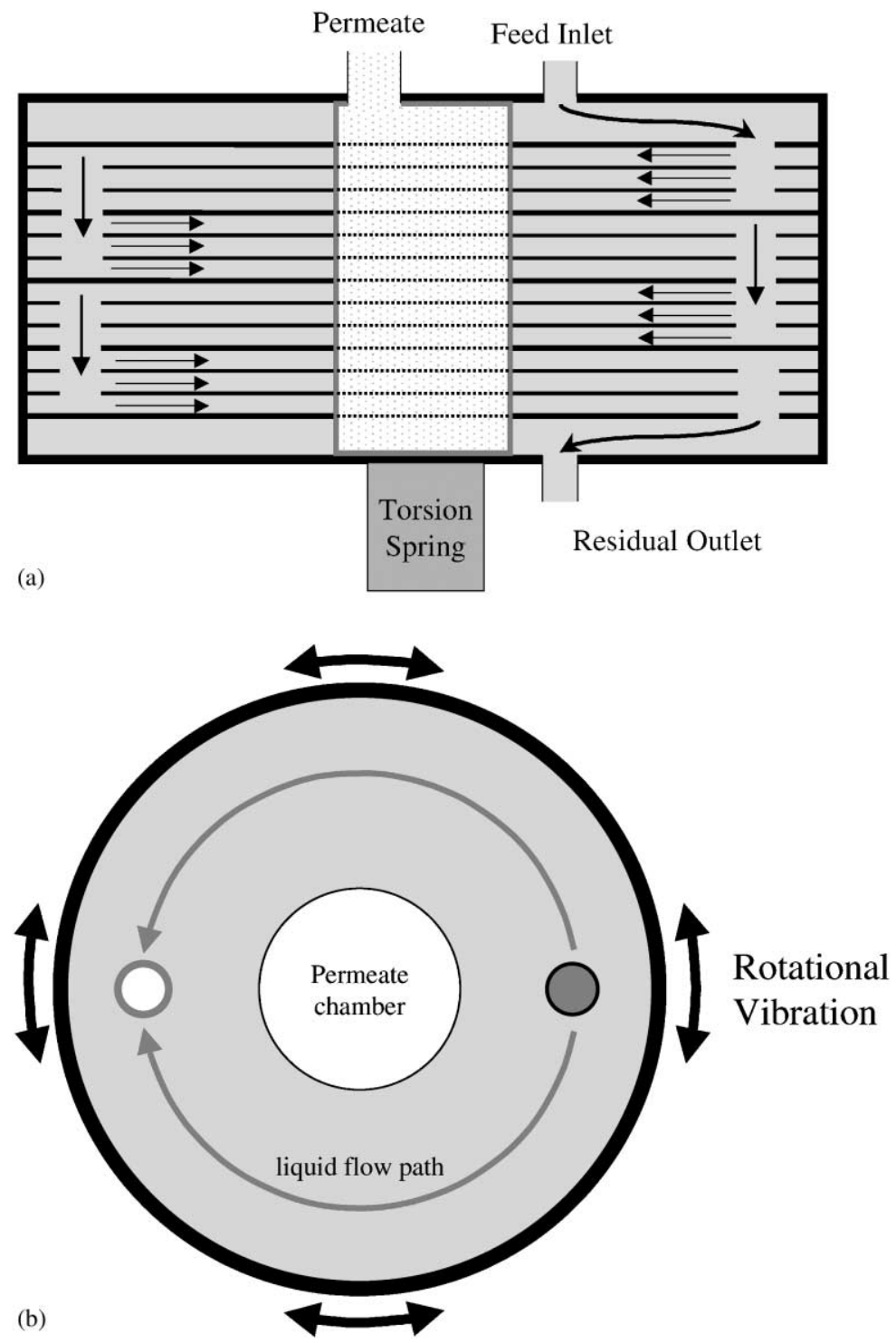

Fig. 3. (a) Schematic side view diagram of a VSEP module with three membrane trays in parallel. (b) Schematic diagram of a cutaway top-view of a VSEP module.

In order to better evaluate the capabilities of the VSEP system for pervaporation-based separations, it was decided that a module should be constructed with typical pervaporation membrane. To this end, a 15 in. i-series module was fabricated by New Logic International using membrane provided by Membrane Technology and Research Inc. (MTR, Menlo Park, CA). The MTR membrane consisted of a thin layer of silicone rubber (circa $10 \mu \mathrm{m}$ thick) supported by a microporous backing. This membrane was equivalent to that available in spiral wound pervaporation and vapor permeation modules manufactured by MTR. Aside from the membrane, this module, to be designated as the MTR1 module, only differed from the CF1010 module in that 13 diverter trays were employed to yield an untapered flow pattern of three 
trays in parallel at all times. All other design characteristics were the same.

The entire pilot system (feed tank, modules, filters, etc.) contained approximately $500 \mathrm{gal}$ of water. The feed solution was prepared by dissolving one or more VOCs in the water or surfactant contained in the feed tank. In the case of MTBE, a saturated solution of MTBE in water was added to the recirculation loop on the feed tank. Due to the low water solubilities exhibited by toluene and the target chlorinated solvents, these chemicals were added neat to the feed tank recirculation loop and allowed to dissolve overnight. At the start of an experiment, concentrations of each VOC were in a range from 10 to $100 \mathrm{mg} / \mathrm{l}$ in the absence of surfactant but as high as $500 \mathrm{mg} / \mathrm{l}$ in the presence of surfactant. System performance, as measured by the fraction of VOC removed or by the overall mass transfer coefficient, was found to be independent of feed VOC concentration.

Past experiments have shown that $1-2 \mathrm{~h}$ of operation are sufficient to reach steady state conditions, after which time sample and permeate collection can begin. Thus, a minimum of $2 \mathrm{~h}$ were allowed to elapse after changes in process conditions and before samples were obtained. After the start-up time had elapsed, feed and residual samples were acquired. In most cases, the feed sample was obtained via a septum port. The needle of an airtight syringe was inserted through a septum port installed on each process line to be sampled. Since the process streams were pressurized, sample was forced into the syringe when the plunger was pulled back, thus, avoiding the creation of vacuum conditions in the syringe which might volatilize the VOCs. After flushing, a slight excess of sample was drawn into the syringe. The syringe needle was then withdrawn from the septum port, excess sample expelled, and the desired sample volume was injected into a volumetric flask of water (either 50 or $100 \mathrm{ml}$ ). When surfactant was present, 3-6 drops of antifoam were added to the volumetric flask to reduce foaming in the purge and trap equipment. The antifoam was prepared daily by diluting $1 \mathrm{~g}$ of Dow antifoam $\mathrm{C}$ with $5 \mathrm{~g}$ water. The volumetric flask was promptly mixed by inverting and shaking, and a portion of the contents was poured into a labeled $40 \mathrm{ml}$ VOA vial, completely filling the vial. The vial was then capped with a Teflon-lined silicone septum. In general, only one dilution of each stream was performed. In some cases, two dilutions were performed to ensure that one set was within the linear calibration range of the GC. The maximum dilution used was 500 -fold $(200 \mu \mathrm{l}$ in $100 \mathrm{ml})$. At the highest surfactant concentrations, a minimum of a 40:1 dilution was applied in order to reduce surfactant concentrations to minimize foam generation during purging. Each dilution was performed in duplicate-starting with acquisition of the sample by syringe. Due to removal of VOC by the pervaporation module, residual samples were obtained, at times, undiluted (in duplicate) by filling a $40 \mathrm{ml}$ vial directly from a valved sampling port. All samples were stored at $4{ }^{\circ} \mathrm{C}$ and analyzed within $24 \mathrm{~h}$. Two sets of feed and residual samples were obtained per set of experimental conditions, generally separated by $1-3 \mathrm{~h}$. During a subset of the pilot experiments, the water flux was determined by measuring the amount of water collected in the permeate between feed sampling events.

\subsection{Analytical}

The undiluted and diluted water samples were analyzed for VOCs using EPA Method 8015, with a Tremetrics 9001 GC equipped with a DB-624 megabore column and a flame ionization detector (FID), Varian Archon Purge and Trap Autosampler, and Tekmar 3000 Purge and Trap Concentrator. A purge vessel heater, set at $40^{\circ} \mathrm{C}$, was employed for samples containing MTBE for enhanced MTBE purge efficiency. Method detection limits were less than $2 \mu \mathrm{g} / \mathrm{l}$ for all VOCs with this method. 1-Bromobutane was added as a surrogate analyte by the purge \& trap autosampler. Surrogate recoveries of $80-120 \%$ were considered acceptable. Daily calibration checks were performed and the calibration was considered verified if the check standard concentration of analyte was within $15 \%$ of the expected concentration. Matrix spikes were performed to monitor the performance of the analytical procedure. For example, MTBE recoveries for weekly matrix spike samples were always in the $95-105 \%$ range. The relative percent difference (RPD) observed for duplicate samples was always less than $5 \%$ and usually less than $2 \%$.

A typical experiment consisted of two or three sets of experimental conditions with two or three feed and residual sampling events (separated by at least $30 \mathrm{~min}$ ) per set of conditions. Variables included feed flow rate, vibration amplitude, feed liquid temperature, 
surfactant concentration, and applied vacuum pressure. Most experiments were duplicated on another day. Thus, most results presented herein are based on the average of individual results from at least four separate sample collection events. When an experiment was not being performed, the feed and residual streams were switched to a 55 gal stainless steel drum which contained the same material as the feed tank, but without VOC. All vibrations were ceased although feed flow and vacuum were maintained. At times, the temperature of the system was lowered during standby periods to reduce water flux.

\section{Results ${ }^{1}$}

Experimental data for the VSEP modules were evaluated based on the single-pass fraction of VOC removed in the module $\left(X_{i}\right)$ as well as the overall VOC mass transfer coefficient $\left(k_{i}\right)$ calculated from the removal and process parameters. The fraction of an individual VOC removed was calculated as follows:

$X_{i}=\frac{C_{\mathrm{Fi}}-C_{\mathrm{Ri}}}{C_{\mathrm{Fi}}}$

where $C_{\mathrm{Fi}}=$ feed concentration of VOC " $i$ " $(\mathrm{mg} / \mathrm{l})$, $C_{\mathrm{Ri}}=$ residual concentration of VOC " $i$ " (mg/l).

The average VOC flux in a membrane module was estimated as [7,12]:

$J_{i}=k_{i} \Delta C_{\mathrm{LM}}$

where $J_{i}=$ average flux of VOC " $i$ ", $k_{i}=$ overall mass transfer coefficient for component " $i$ ", $\Delta C_{\mathrm{LM}}=$ $\log$ mean concentration of " $i$ " and defined as

$\Delta C_{\mathrm{LM}}=\frac{C_{\mathrm{Fi}}-C_{\mathrm{Ri}}}{\ln \left(C_{\mathrm{Fi}} / C_{\mathrm{Ri}}\right)}$

Inherent in Eqs. (2) and (3) is the assumption that the permeate concentration (or the equivalent liquid phase concentration in equilibrium with the permeate vapor concentration) is negligible compared to the feed liquid concentration. This is believed to be the case for the conditions of the subject experiments.

By performing a mass balance around the module, the mass transfer coefficient can be calculated

\footnotetext{
${ }^{1}$ Note: unless otherwise indicated, error bars and tolerances represent a $95 \%$ confidence interval.
}

according to the following relationship [7]:

$k_{i}=\frac{-Q}{A} \ln \left(\frac{C_{\mathrm{Ri}}}{C_{\mathrm{Fi}}}\right)$

where $A=$ membrane area $\left(\mathrm{m}^{2}\right), Q=$ liquid flow rate $\left(\mathrm{m}^{3} / \mathrm{s}\right)$ (here, $\left.1 \mathrm{gpm}=6.31 \times 10^{-5} \mathrm{~m}^{3} / \mathrm{s}\right)$.

Eq. (4) has been shown to be valid even for the removal of VOCs from surfactant solutions [7]. In simplified terms, $k_{i}$ can be thought of as a concentration normalized flux that is generally independent of concentration. Thus, process changes which increase $k_{i}$ should result in a smaller and less expensive system. Through the resistances-in-series approach, $k_{i}$ can be related to the liquid boundary layer mass transfer coefficient $\left(k_{i}^{\mathrm{L}}\right)$, the membrane mass transfer coefficient $\left(k_{i}^{\mathrm{M}}\right)$, and vapor phase boundary layer mass transfer coefficient $\left(k_{i}^{\mathrm{V}}\right)$ as follows $[13,14]$ :

$\frac{1}{k_{i}}=\frac{1}{k_{i}^{\mathrm{L}}}+\frac{1}{k_{i}^{\mathrm{M}}}+\frac{1}{k_{i}^{\mathrm{V}}}$

When the vapor phase is generated as a vacuum, the last term is quite small and is commonly disregarded. The liquid boundary layer resistance is dependent on a number of variables including fluid velocity, fluid viscosity, fluid density, compound diffusivity, and module geometry. Membrane resistance is a function of the membrane thickness, permeability of a compound through the membrane, and the Henry's law coefficient for that compound. Typically, for aqueous solutions, the liquid phase resistance dominates mass transport of hydrophobic and volatile VOCs (compounds with high Henry's law constants) while membrane resistance dominates for hydrophilic organic compounds or when a thick membrane is used.

\subsection{CF1010 module results}

A series of experiments was performed in the fall of 1999 to assess the impact of the surfactant employed during the Camp Lejeune SEAR demonstration on VOC removal performance of the CF1010 module. Process variables investigated included surfactant concentration, vibration amplitude, temperature, and flow rate. The feed solution contained five VOCs: 1,1,1-TCA, TCE, toluene, PCE, and $p$-xylene. The effect of surfactant concentration (Alfoterra145) on removal of 1,1,1-TCA, toluene, and PCE at $40^{\circ} \mathrm{C}$, 


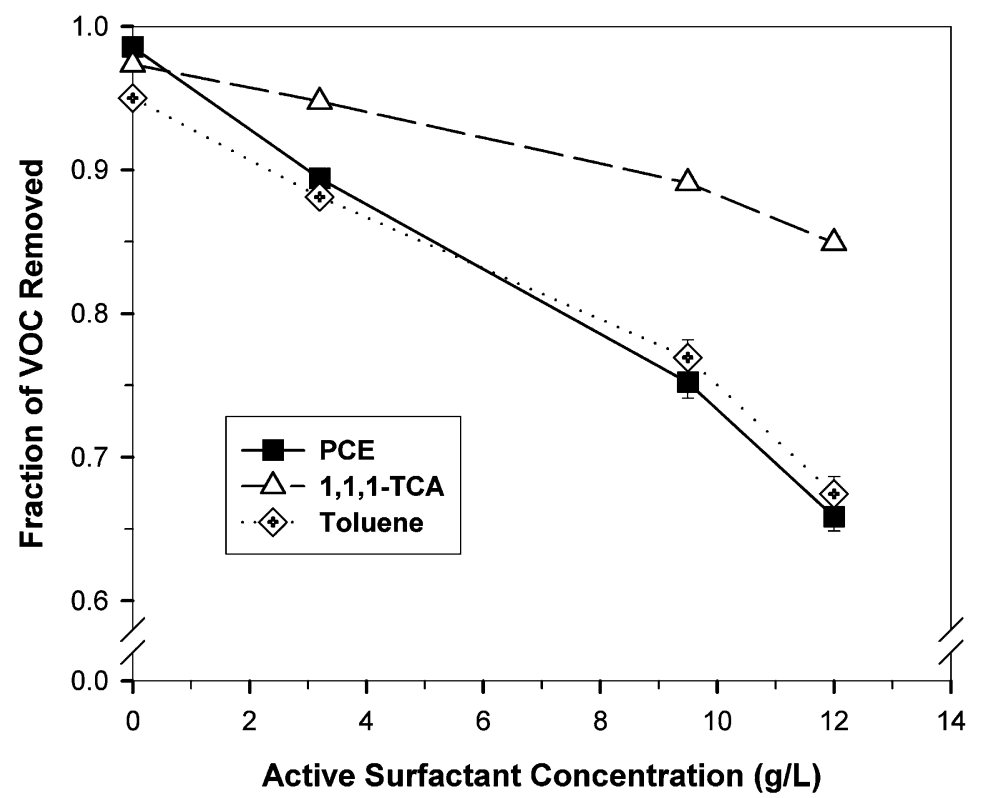

Fig. 4. Effect of Alfoterra145 surfactant concentration on the single-pass fraction of VOC removed by the CF1010 VSEP module at 1 gpm, $40^{\circ} \mathrm{C}, 0.5$ in. vibration amplitude.

$1 \mathrm{gpm}$, and $0.5 \mathrm{in}$. vibration amplitude is shown in Fig. 4. Removal values for all five VOCs in the absence of surfactant and at the maximum surfactant concentration, $12 \mathrm{~g} / \mathrm{l}$, are provided in Table 1 . Removal efficiency was reduced for all VOCs as surfactant concentration increased. The relative amount of reduction increased as the hydrophobicity of the VOC increased with 1,1,1-TCA and $p$-xylene being the least and most impacted, respectively. A number of papers have reported the effect of VOC type and surfactant type/concentration on the partitioning of VOC between surfactant micelles and the extramicellar region as well as the effect of this partitioning on pervaporation performance $[6-8,10,11,15-23]$. In particular, the partitioning of 1,1,1-TCA, TCE, toluene, and PCE in Alfoterra145 solutions was previously reported by our group [20]. In that work, the extramicellar fraction of VOC $\left(f_{\text {ex }}\right)$ was found to decrease according to the trend 1,1,1-TCA $>$ TCE $>$ toluene $>$ PCE. Thus, the more hydrophobic PCE was more inclined to partition into the Alfoterra145 micelles than the other VOCs. If a membrane is immersed in a VOC solution containing surfactant micelles which yields a particular extramicellar VOC concentration, then the

Table 1

Effect of surfactant on VOC removal by CF1010 Module at $1 \mathrm{gpm}, 40^{\circ} \mathrm{C}$, and $0.5 \mathrm{in}$. vibration

\begin{tabular}{|c|c|c|c|c|}
\hline \multirow[t]{2}{*}{ VOC } & \multicolumn{2}{|c|}{ Fraction of VOC removed in the presence of: } & \multirow{2}{*}{$\begin{array}{l}1 / f_{\mathrm{ex}^{\mathrm{a}}}(12 \mathrm{~g} / 1 \\
\text { Alfoterra145) }\end{array}$} & \multirow{2}{*}{$\begin{array}{l}\text { Relative membrane area increase } \\
\text { required for } 12 \mathrm{~g} / 1 \text { Alfoterra } 145^{\mathrm{b}}\end{array}$} \\
\hline & No surfactant & $12 \mathrm{~g} / 1$ Afoterra145 & & \\
\hline $1,1,1-\mathrm{TCA}$ & $0.9734 \pm 0.0015$ & $0.8491 \pm 0.0047$ & 2.4 & $1.9 \times$ \\
\hline TCE & $0.9704 \pm 0.0024$ & $0.7898 \pm 0.0091$ & 2.7 & $2.3 \times$ \\
\hline Toluene & $0.9500 \pm 0.0048$ & $0.6744 \pm 0.0122$ & 3.2 & $2.7 \times$ \\
\hline PCE & $0.9857 \pm 0.0008$ & $0.6586 \pm 0.0103$ & 7.6 & $4.0 \times$ \\
\hline$p$-Xylene & $0.9625 \pm 0.0028$ & $0.5138 \pm 0.0074$ & 9.1 & $4.6 \times$ \\
\hline
\end{tabular}

${ }^{\text {a }}$ Estimated from values provided in [20].

b Relative to that required for the "no surfactant" system-in order to achieve the same fraction of VOC removal. 
equilibrium concentration of VOC in the membrane will be the same as for the same membrane immersed in a solution containing no surfactant, but at a VOC concentration equal to that of the extramicellar VOC concentration of the surfactant solution. If pervaporation operates as a vapor-liquid equilibrium process, then relative efficiency should be reduced by a factor $f_{\text {ex }}$ upon addition of surfactant (via $k_{i}$ ). Therefore, if a certain VOC removal is desired, then the membrane area required for a surfactant solution must be increased, according to Eq. (4), by a factor of $1 / f_{\mathrm{ex}}$ relative to that required in the absence of surfactant. Values of $1 / f_{\text {ex }}$ calculated for each VOC studied are provided in Table 1.

Due to the impact of the liquid boundary layer, VOC concentrations at the membrane are reduced from those in the bulk. In addition, it has been proposed that the surfactant micelles act as reservoirs for VOC in the boundary layer, releasing VOC as the extramicellar VOC concentration decreases towards the membrane $[7,11,23]$. As a result, the concentration of available VOC at the membrane surface is greater than would be predicted by simply reducing the nonsurfactant mass transfer coefficient by the factor $f_{\text {ex }}$. This is also true in the present case. Using the VOC removal performance reported in Table 1, the increase in membrane area of the CF1010 module required to raise VOC removal for a $12 \mathrm{~g} / \mathrm{l}$ Alfoterra145 solution to the same level as that observed in the absence of surfactant was calculated. The result is shown in the last column of Table 1 and can be compared to the values of $1 / f_{\text {ex }}$ also provided in the table. For example, based on the surrogate pervaporation experiments, a VSEP module containing approximately $40 \mathrm{~m}^{2}$ would be required to achieve $98.6 \%$ PCE removal from a solution containing $12 \mathrm{~g} / \mathrm{l}$ Alfoterra145 (assuming the same general characteristics of the CF1010 module) while only $10 \mathrm{~m}^{2}$ was required to achieve the same removal in the absence of surfactant. According to the partitioning $1 / f_{\text {ex }}$ data, $76 \mathrm{~m}^{2}$ would be required to remove 98.6\% PCE in the presence of $12 \mathrm{~g} / \mathrm{l}$ Alfoterra145almost twice the amount which would actually be required. The area increase required for the $12 \mathrm{~g} / \mathrm{l}$ Alfoterra145 system exhibits the same increasing trend as $1 / f_{\text {ex }}$, i.e. $1,1,1-\mathrm{TCA}<\mathrm{TCE}<$ toluene $<$ PCE $<p$-xylene. However, in all cases, the area increase is smaller than $1 / f_{\text {ex }}$, thus, corroborating previous observations that pervaporation efficiency is not reduced to the same extent as might be predicted from equilibrium partitioning data.

One objective of the surrogate testing was to compare surrogate results with those obtained during the field demonstration at Camp Lejeune [11]. The conditions used to obtain the surrogate data presented in Fig. 4 are most representative of those encountered at Camp Lejeune: $1 \mathrm{gpm}, 40^{\circ} \mathrm{C}$, and $0.5 \mathrm{in}$. vibration amplitude. During the Camp Lejeune demonstration, the CF1010 module achieved a fractional PCE removal of $0.9887 \pm 0.0019$ in the absence of surfactant and a removal of $0.655 \pm 0.026$ during the surfactant plateau when Alfoterra145 concentrations averaged $10 \mathrm{~g} / \mathrm{l}$. As presented in Fig. 4, this same CF1010 module achieved fractional PCE removals of $0.9857 \pm 0.0008,0.752 \pm 0.011$, and $0.659 \pm 0.010$, for surrogate solutions containing $0,9.5$ and $12 \mathrm{~g} / \mathrm{l} \mathrm{Al}$ foterra145, respectively. The surrogate and field data closely agree when no surfactant is present. Field data measured during the surfactant plateau are somewhat lower than comparable surrogate data, possibly due to the accumulation of surfactant material in the permeate zone of the CF1010 module reported during the field project [11]. The source of the leak was fixed and the accumulated surfactant was removed prior to initiation of the surrogate experiments. In addition, to reduce the severity of the leak, a vibration amplitude of $0.25 \mathrm{in}$. was employed during much of the surfactant plateau. Similar surrogate experiments performed at $40^{\circ} \mathrm{C}, 1 \mathrm{gpm}$, and $0.25 \mathrm{in}$. vibration amplitude yielded fractional PCE removals of $0.697 \pm 0.010$ and $0.598 \pm 0.007$ for surrogate solutions containing 9.5 and $12 \mathrm{~g} / \mathrm{l}$ Alfoterra145, respectively. These values are more consistent with the field observations.

As noted from laboratory-scale VSEP experiments [10], VSEP vibration amplitude can significantly alter VOC removal efficiency. The effect of vibration amplitude on PCE removal from surrogate SEAR solutions for the CF1010 module is displayed in Fig. 5 as a function of Alfoterra145 concentration at $1 \mathrm{gpm}$ and $40^{\circ} \mathrm{C}$. For all surfactant levels, raising vibration amplitude from 0 to $0.25 \mathrm{in}$. resulted in significant performance gains. Beyond 0.25 in., PCE removal continued to increase, but the gains were not as substantial, indicating that the dominant mass transfer resistance was in transition from the liquid boundary layer to the membrane. The values of the overall mass transport coefficient corresponding to VOC removals 


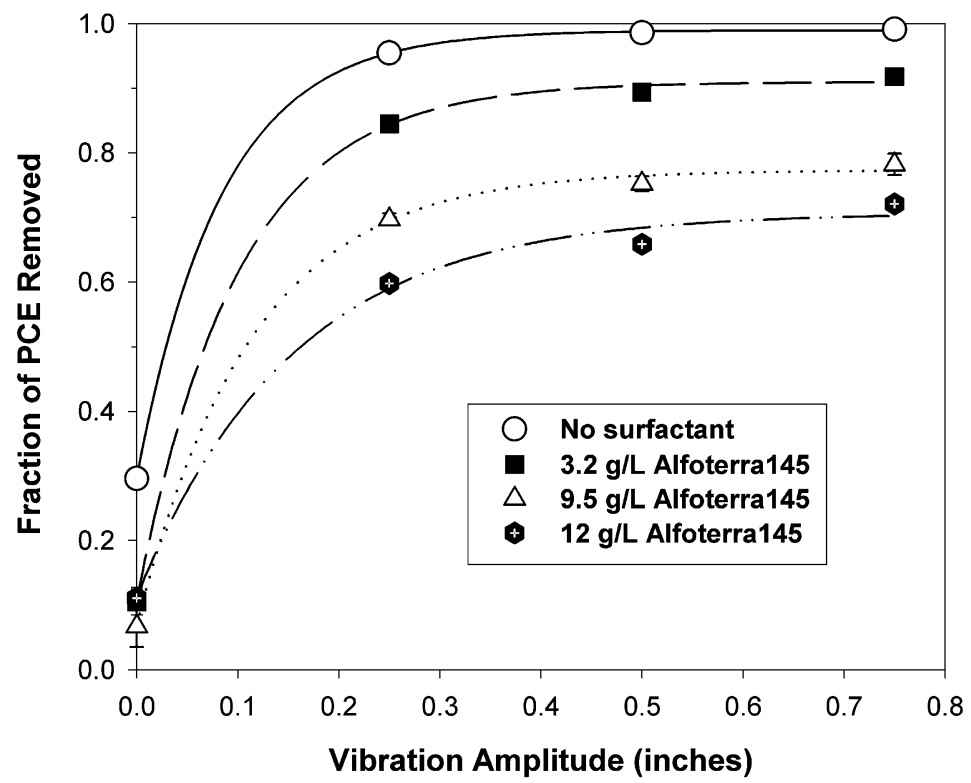

Fig. 5. Effect of vibration amplitude on the single-pass fraction of PCE removed by the CF1010 VSEP module at 1 gpm and $40{ }^{\circ} \mathrm{C}$.

measured in the absence of surfactant for the CF1010 module are provided in Table 2 . The data in the table indicate that $k_{\mathrm{PCE}}$ increased by $790 \%$ in the transition from no vibration to $0.25 \mathrm{in}$. vibration (at $40^{\circ} \mathrm{C}$, $1 \mathrm{gpm}$, no surfactant), but only $38 \%$ from 0.25 to 0.5 in. and only $12 \%$ from 0.5 to 0.75 in. Similar gains were observed for 1,1,1-TCA and toluene. However, $k_{\mathrm{MTBE}}$ was much less sensitive to vibration amplitude. As detailed elsewhere [24], the low Henry's law constant of MTBE causes transport of this compound to be more membrane controlled than other VOCs studied. As a result, reductions in the boundary layer resistance will have less of an impact on the overall mass transfer coefficient of MTBE.

Flow rate and temperature also affected VOC removal with the CF1010 module, but not as dramatically as did vibration amplitude. Higher temperatures resulted in increases in the overall mass transfer coefficient for all VOCs. Of the VOCs studied, MTBE exhibited the most dramatic performance gains with increasing temperature due to the strong response of the Henry's law constant of MTBE to temperature [24]. The manufacturer of the VSEP recommends maintaining a minimum flow rate of $1 \mathrm{gpm}$ through each tray to minimize the formation of dead zones in the feed flow path. While this guideline was established for normal filtration applications, it likely can be applied to pervaporation systems as well. In experiments with the CF1010 module, the flow rate per tray ranged from 0.08 to $0.25 \mathrm{gpm}$ when the total flow rate was $1 \mathrm{gpm}$ and had a range of $0.24-0.72 \mathrm{gpm}$ at the maximum study flow rate of $2.88 \mathrm{gpm}$. Efficiency gains resulting from increasing flow rate were observed even at the maximum vibration amplitude and temperature. These gains are larger than might be expected due to reductions in the liquid boundary layer (using a Leveque-type correlation) and are most likely due to improved flow distribution. Thus, the maximum mass transfer coefficient is expected to occur at highest vibration amplitude, highest flow rate, and highest temperature.

Pressure and temperature drops through the CF1010 module were too small to be accurately measured with the installed gauges. The pressure drop appeared to be less than 3 psi for all conditions while the temperature drop appeared to be less than $1^{\circ} \mathrm{C}$. The water flux, measured in the absence of surfactant and at a vacuum of approximately 1 Torr in the fall of 1999 , was $1.6 \times 10^{-2}, 2.8 \times 10^{-2}$ and $3.4 \times 10^{-2} \mathrm{~kg} / \mathrm{m}^{2} \mathrm{~h}$ at 40 , 50 and $60^{\circ} \mathrm{C}$, respectively. Subsequent measurements 
Table 2

VOC Mass transfer coefficients $\left(k_{i}\right)$ for CF1010 module with no surfactant present

\begin{tabular}{|c|c|c|c|c|c|c|}
\hline \multirow{2}{*}{$\begin{array}{l}\text { Vibration } \\
\text { amplitude (in.) }\end{array}$} & \multirow{2}{*}{$\begin{array}{l}\text { Temperature } \\
\left({ }^{\circ} \mathrm{C}\right)\end{array}$} & \multirow{2}{*}{$\begin{array}{l}\text { Flow rate } \\
(\mathrm{gpm})\end{array}$} & \multicolumn{4}{|c|}{ Overall VOC mass transfer coefficient $(\mathrm{m} / \mathrm{s})$} \\
\hline & & & $1,1,1-\mathrm{TCA}$ & Toluene & PCE & MTBE \\
\hline 0 & $\begin{array}{l}40 \\
40 \\
60 \\
60 \\
80 \\
80\end{array}$ & $\begin{array}{l}1.0 \\
2.0 \\
1.0 \\
2.0 \\
1.0 \\
2.0\end{array}$ & $\begin{array}{l}(2.18 \pm 0.07) \times 10^{-6 a} \\
(2.97 \pm 0.22) \times 10^{-6 b} \\
(3.19 \pm 0.06) \times 10^{-6 b} \\
(4.64 \pm 0.16) \times 10^{-6 b} \\
(4.55 \pm 0.05) \times 10^{-6 b} \\
(6.55 \pm 0.02) \times 10^{-6 b}\end{array}$ & $\begin{array}{l}(2.13 \pm 0.06) \times 10^{-6 a} \\
(2.84 \pm 0.05) \times 10^{-6 b} \\
(3.18 \pm 0.04) \times 10^{-6 b} \\
(4.52 \pm 0.13) \times 10^{-6 b} \\
(4.35 \pm 0.04) \times 10^{-6 b} \\
(6.30 \pm 0.04) \times 10^{-6 b}\end{array}$ & $\begin{array}{l}(2.20 \pm 0.07) \times 10^{-6 a} \\
(3.01 \pm 0.19) \times 10^{-6 b} \\
(3.23 \pm 0.05) \times 10^{-6 b} \\
(4.65 \pm 0.18) \times 10^{-6 b} \\
(4.42 \pm 0.08) \times 10^{-6 b} \\
(6.66 \pm 0.25) \times 10^{-6 b}\end{array}$ & $\begin{array}{l}(1.08 \pm 0.03) \times 10^{-6 b} \\
(1.33 \pm 0.02) \times 10^{-6 b} \\
(1.98 \pm 0.04) \times 10^{-6 b} \\
(2.57 \pm 0.07) \times 10^{-6 b} \\
(2.86 \pm 0.06) \times 10^{-6 b} \\
(3.65 \pm 0.11) \times 10^{-6 b}\end{array}$ \\
\hline 0.25 & $\begin{array}{l}40 \\
60\end{array}$ & $\begin{array}{l}1.0 \\
1.0\end{array}$ & $\begin{array}{l}(1.68 \pm 0.06) \times 10^{-5} \\
(2.39 \pm 0.02) \times 10^{-5}\end{array}$ & $\begin{array}{l}(1.43 \pm 0.08) \times 10^{-5} \\
(2.21 \pm 0.10) \times 10^{-5}\end{array}$ & $\begin{array}{l}(1.96 \pm 0.07) \times 10^{-5} \\
(2.79 \pm 0.02) \times 10^{-5}\end{array}$ & \\
\hline 0.5 & $\begin{array}{l}40 \\
40 \\
40 \\
60 \\
60 \\
80 \\
80\end{array}$ & $\begin{array}{l}1.0 \\
2.0 \\
2.88 \\
1.0 \\
2.0 \\
1.0 \\
2.0\end{array}$ & $\begin{array}{l}(2.38 \pm 0.07) \times 10^{-5 a} \\
(2.73 \pm 0.03) \times 10^{-5 b} \\
(2.70 \pm 0.10) \times 10^{-5} \\
(3.08 \pm 0.05) \times 10^{-5 b} \\
(3.96 \pm 0.06) \times 10^{-5 b} \\
(3.70 \pm 0.09) \times 10^{-5 b} \\
(4.70 \pm 0.01) \times 10^{-5 b}\end{array}$ & $\begin{array}{l}(1.90 \pm 0.05) \times 10^{-5 a} \\
(2.16 \pm 0.03) \times 10^{-5 b} \\
(2.29 \pm 0.10) \times 10^{-5} \\
(2.68 \pm 0.03) \times 10^{-5 b} \\
(3.41 \pm 0.04) \times 10^{-5 b} \\
(3.41 \pm 0.05) \times 10^{-5 b} \\
(4.30 \pm 0.02) \times 10^{-5 b}\end{array}$ & $\begin{array}{l}(2.70 \pm 0.05) \times 10^{-5 a} \\
(3.26 \pm 0.02) \times 10^{-5 b} \\
(3.42 \pm 0.10) \times 10^{-5} \\
(3.17 \pm 0.06) \times 10^{-5 b} \\
(4.76 \pm 0.06) \times 10^{-5 b} \\
(3.47 \pm 0.09) \times 10^{-5 b} \\
(5.73 \pm 0.00) \times 10^{-5 b}\end{array}$ & $\begin{array}{l}(2.76 \pm 0.12) \times 10^{-6 b} \\
(2.80 \pm 0.15) \times 10^{-6 b} \\
(5.91 \pm 0.15) \times 10^{-6 b} \\
(6.69 \pm 0.01) \times 10^{-6 b} \\
(1.01 \pm 0.01) \times 10^{-5 b} \\
(1.12 \pm 0.01) \times 10^{-5 b}\end{array}$ \\
\hline 0.75 & $\begin{array}{l}40 \\
40 \\
60 \\
60\end{array}$ & $\begin{array}{l}1.0 \\
2.88 \\
1.0 \\
2.8\end{array}$ & $\begin{array}{l}(2.48 \pm 0.06) \times 10^{-5} \\
(3.05 \pm 0.02) \times 10^{-5} \\
(3.22 \pm 0.18) \times 10^{-5} \\
(4.55 \pm 0.11) \times 10^{-5}\end{array}$ & $\begin{array}{l}(2.06 \pm 0.12) \times 10^{-5} \\
(2.55 \pm 0.02) \times 10^{-5} \\
(3.08 \pm 0.10) \times 10^{-5} \\
(4.39 \pm 0.05) \times 10^{-5}\end{array}$ & $\begin{array}{l}(3.02 \pm 0.17) \times 10^{-5} \\
(3.93 \pm 0.02) \times 10^{-5} \\
(4.04 \pm 0.17) \times 10^{-5} \\
(5.56 \pm 0.16) \times 10^{-5}\end{array}$ & \\
\hline
\end{tabular}

All other data from fall 1999 .

${ }^{\text {a }}$ Combined data from fall 1999 and spring 2000.

${ }^{\mathrm{b}}$ Only spring 2000 data available for this set of conditions. 
Table 3

VOC Mass transfer coefficients $\left(k_{i}\right)$ for MTR1 VSEP module with no surfactant present (unless otherwise indicated, permeate pressure was 8 and 22 Torr at 40 and $60^{\circ} \mathrm{C}$, respectively)

\begin{tabular}{|c|c|c|c|c|c|c|}
\hline \multirow{2}{*}{$\begin{array}{l}\text { Vibration } \\
\text { amplitude (in.) }\end{array}$} & \multirow{2}{*}{$\begin{array}{l}\text { Temperature } \\
\left({ }^{\circ} \mathrm{C}\right)\end{array}$} & \multirow{2}{*}{$\begin{array}{l}\text { Flow rate } \\
\text { (gpm) }\end{array}$} & \multicolumn{4}{|c|}{ Overall VOC mass transfer coefficient $(\mathrm{m} / \mathrm{s})$} \\
\hline & & & $1,1,1-\mathrm{TCA}$ & Toluene & PCE & MTBE \\
\hline 0 & 40 & 1.0 & $(3.29 \pm 0.04) \times 10^{-6}$ & $(3.66 \pm 0.09) \times 10^{-6}$ & $(3.62 \pm 0.08) \times 10^{-6}$ & $(2.38 \pm 0.11) \times 10^{-6}$ \\
\hline 0 & 40 & 2.0 & $(5.37 \pm 0.14) \times 10^{-6}$ & $(5.53 \pm 0.07) \times 10^{-6}$ & $(5.60 \pm 0.15) \times 10^{-6}$ & $(3.01 \pm 0.28) \times 10^{-6}$ \\
\hline 0 & 60 & 1.0 & $(5.01 \pm 0.11) \times 10^{-6}$ & $(5.30 \pm 0.04) \times 10^{-6}$ & $(5.23 \pm 0.06) \times 10^{-6}$ & $(3.27 \pm 0.17) \times 10^{-6}$ \\
\hline \multicolumn{3}{|c|}{ Same as above, but 55 Torr } & $(5.01 \pm 0.10) \times 10^{-6}$ & $(5.26 \pm 0.02) \times 10^{-6}$ & $(5.23 \pm 0.03) \times 10^{-6}$ & $(3.22 \pm 0.10) \times 10^{-6}$ \\
\hline 0 & 60 & 2.0 & $(8.19 \pm 0.18) \times 10^{-6}$ & $(8.44 \pm 0.09) \times 10^{-6}$ & $(8.41 \pm 0.17) \times 10^{-6}$ & $(5.06 \pm 0.16) \times 10^{-6}$ \\
\hline 0.5 & 40 & 1.0 & $(3.28 \pm 0.05) \times 10^{-5}$ & $(2.75 \pm 0.05) \times 10^{-5}$ & $(3.14 \pm 0.06) \times 10^{-5}$ & $(1.21 \pm 0.01) \times 10^{-5}$ \\
\hline 0.5 & 40 & 2.0 & $(3.64 \pm 0.06) \times 10^{-5}$ & $(3.20 \pm 0.05) \times 10^{-5}$ & $(3.76 \pm 0.05) \times 10^{-5}$ & $(1.25 \pm 0.02) \times 10^{-5}$ \\
\hline 0.5 & 60 & 1.0 & $(3.94 \pm 0.13) \times 10^{-5}$ & $(3.70 \pm 0.12) \times 10^{-5}$ & $(3.34 \pm 0.10) \times 10^{-5}$ & $(2.54 \pm 0.02) \times 10^{-5}$ \\
\hline \multicolumn{3}{|c|}{ Same as above, but 55 Torr } & $(4.12 \pm 0.32) \times 10^{-5}$ & $(3.77 \pm 0.22) \times 10^{-5}$ & $(3.33 \pm 0.21) \times 10^{-5}$ & $(2.41 \pm 0.03) \times 10^{-5}$ \\
\hline 0.5 & 60 & 2.0 & $(6.34 \pm 0.14) \times 10^{-5}$ & $(5.65 \pm 0.11) \times 10^{-5}$ & $(5.76 \pm 0.10) \times 10^{-5}$ & $(3.21 \pm 0.12) \times 10^{-5}$ \\
\hline 0.75 & 40 & 1.0 & $(3.91 \pm 0.05) \times 10^{-5}$ & $(3.18 \pm 0.05) \times 10^{-5}$ & $(3.70 \pm 0.12) \times 10^{-5}$ & $(1.32 \pm 0.03) \times 10^{-5}$ \\
\hline 0.75 & 60 & 1.0 & $(4.62 \pm 0.14) \times 10^{-5}$ & $(4.29 \pm 0.16) \times 10^{-5}$ & $(3.78 \pm 0.14) \times 10^{-5}$ & $(2.93 \pm 0.07) \times 10^{-5}$ \\
\hline 1.0 & 40 & 1.0 & $(4.73 \pm 0.34) \times 10^{-5}$ & $(3.72 \pm 0.12) \times 10^{-5}$ & $(4.10 \pm 0.42) \times 10^{-5}$ & $(1.42 \pm 0.04) \times 10^{-5}$ \\
\hline 1.0 & 60 & 1.0 & $(5.79 \pm 0.03) \times 10^{-5}$ & $(5.22 \pm 0.02) \times 10^{-5}$ & $(4.66 \pm 0.04) \times 10^{-5}$ & $(3.14 \pm 0.10) \times 10^{-5}$ \\
\hline 1.0 & 60 & 2.0 & $1.08 \times 10^{-4 \mathrm{a}}$ & $9.18 \times 10^{-5 a}$ & $9.06 \times 10^{-5 a}$ & $3.61 \times 10^{-5 \mathrm{a}}$ \\
\hline
\end{tabular}

${ }^{a}$ Only one data point obtained prior to module failure. 
in the spring of 2000 indicated a water flux of $2.7 \times 10^{-2} \mathrm{~kg} / \mathrm{m}^{2} \mathrm{~h}$ at $60^{\circ} \mathrm{C}$. These values are consistent with values obtained with other silicone rubber membranes.

\subsection{MTR1 module results}

For several reasons, the design of the MTR1 module should result in higher mass transport coefficients than the CF1010 module. First, with three trays in parallel throughout, the flow rate per tray for the MTR1 module will be higher for an equivalent total feed flow rate. Thus, flow distribution will be improved and the baseline liquid boundary layer resistance will be reduced. Second, the significantly thinner silicone layer of the MTR membrane $(10 \mu \mathrm{m}$ versus $254 \mu \mathrm{m})$ will reduce the membrane mass transfer resistance, thereby raising the maximum achievable overall mass transfer coefficient. By comparing the data presented in Tables 2 and 3 for the CF1010 and MTR1 modules, respectively, the effect of these changes can be seen. Under the same operating conditions, $k_{i}$ observed with the MTR1 module was always greater than that observed with the CF1010 module. For example, under the least favorable conditions evaluated (i.e. no vibration, $\left.40^{\circ} \mathrm{C}, 1 \mathrm{gpm}\right), k_{i}$ was $51-120 \%$ higher with the MTR1 module than with the CF1010 module, depending upon the VOC. Of the VOCs studied, MTBE removal was most improved in the MTR1 module, increasing by up to $340 \%$ under the same general operating conditions. The relative effect on $k_{i}$ of increasing vibration amplitude from 0 to $0.5 \mathrm{in}$. (at $40^{\circ} \mathrm{C}, 1 \mathrm{gpm}$ ) for $1,1,1-\mathrm{TCA}$, toluene, and PCE was comparable for both modules with $k_{i}$ increasing by approximately an order of magnitude. However, for the same amplitude change, $k_{i}$ for MTBE increased by $410 \%$ with the MTR1 module but only $155 \%$ with the CF1010 module.

The effect of vibration amplitude on $k_{i}$ for 1,1,1-TCA and MTBE for the MTR1 module is presented graphically in Figs. 6 and 7, respectively. These figures bear witness to the effect of flow rate, vibration amplitude, temperature, and VOC type on pervaporation performance. As noted above, $k_{i}$ for both VOCs increases significantly as vibration amplitude increases from 0 to $0.5 \mathrm{in}$. Values of $k_{i}$ continues to increase as amplitude rises above 0.5 in., but gains are less dramatic, especially for MTBE. Increasing temperature from 40 to $60{ }^{\circ} \mathrm{C}$ results in a slight increase in $k_{i}$ for 1,1,1-TCA, but a substantial increase

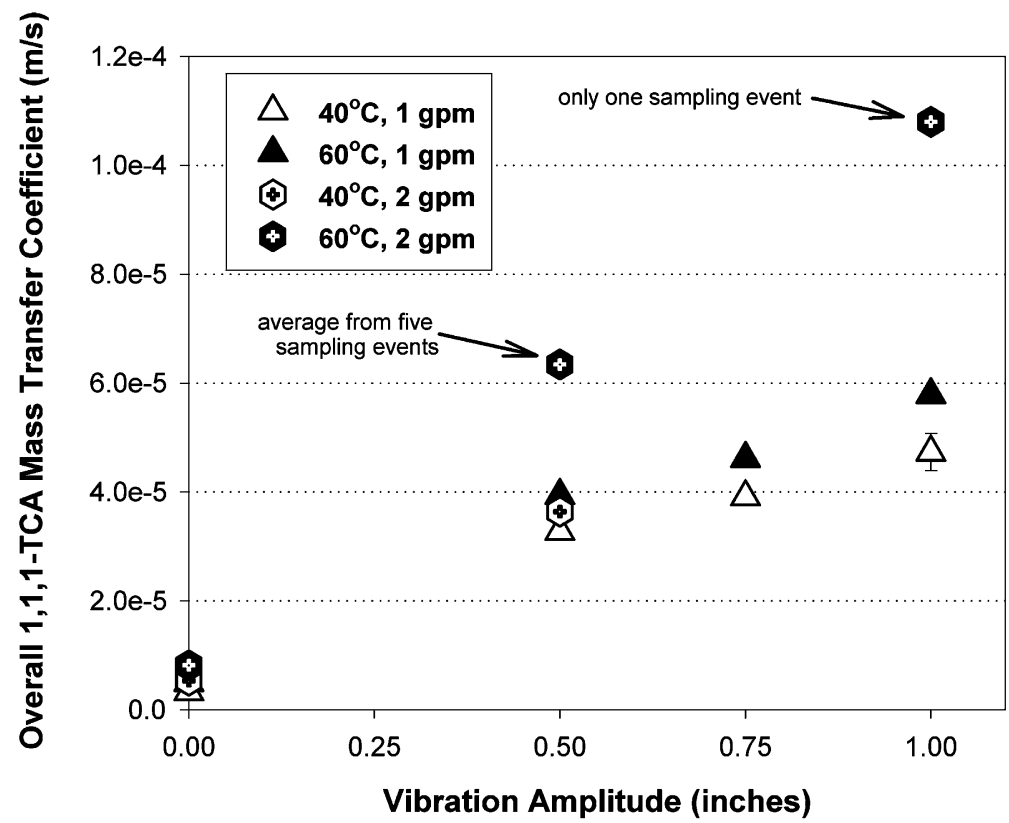

Fig. 6. Overall mass transfer coefficient of 1,1,1-TCA as a function of vibration amplitude, flow rate, and temperature for the MTR1 module. 


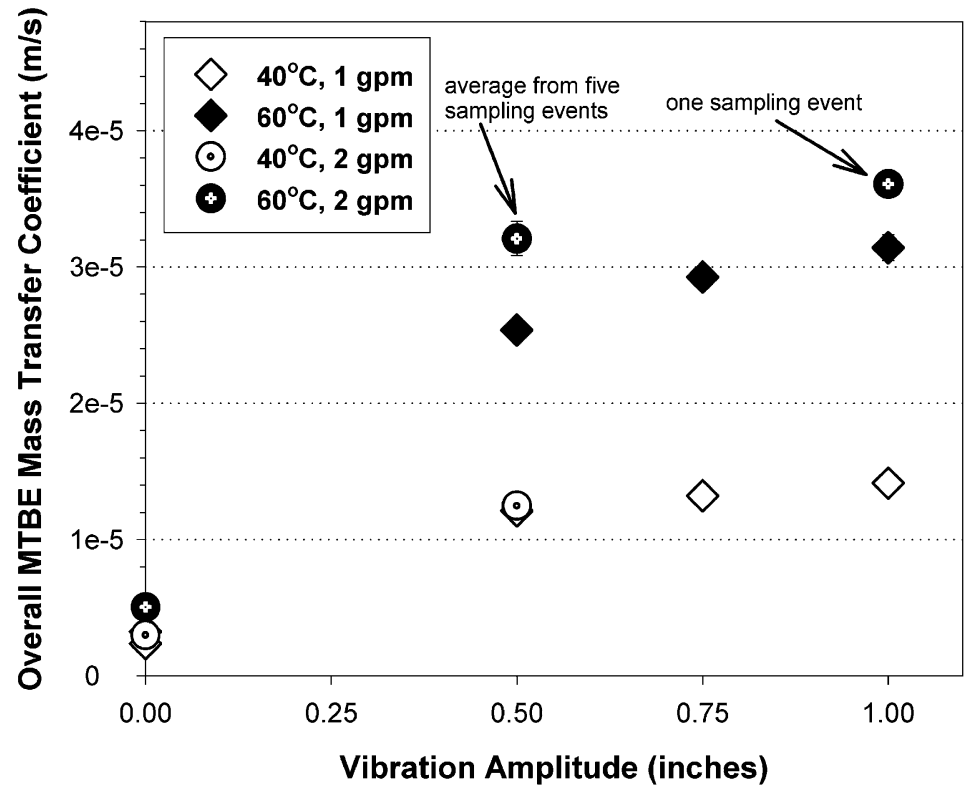

Fig. 7. Overall mass transfer coefficient of MTBE as a function of vibration amplitude, flow rate, and temperature for the MTR1 module.

in $k_{i}$ for MTBE. Increasing flow rate yielded mixed results, depending upon the other process conditions. For example, at $40^{\circ} \mathrm{C}$, increasing flow from 1 to $2 \mathrm{gpm}$ yielded a marginal performance increase for all VOCs, yet the same flow rate change at $60^{\circ} \mathrm{C}$ resulted in quite an appreciable increase in $k_{i}$ for $1,1,1-\mathrm{TCA}$ (as well as for toluene, PCE, and TCE). Similarly, an analysis of data for the CF1010 module indicates that increases in flow rate yielded more significant performance gains at higher temperatures than at lower temperatures.

Unfortunately, the overlapping effects of temperature, flow rate, and vibration, make analysis of only one variable quite difficult. For example, raising temperature will increase the Henry's law constant of the VOC, thereby altering the membrane mass transport coefficient. At the same time, raising temperature reduces solution viscosity, which will change both the flow distribution patterns and the impact of both vibrations and flow on liquid boundary resistance. Increasing flow will alter the liquid boundary layer as well as flow distribution. Finally, vibration amplitude directly impacts the liquid boundary layer resistance but will likely also effect flow distribution. For this reason, we have not attempted to model the effects of process vari- ables on $k_{i}$. However, based on a qualitative analysis (attempting to correct for membrane resistance), the liquid boundary layer mass transfer coefficient appears to vary with the square root of the vibration amplitude.

The performance of the MTR1 module can be compared to previously reported results obtained with a similar membrane $(20 \mu \mathrm{m}$ silicone) in a laboratoryscale VSEP and in spiral wound modules $[7,10,24]$. Due to permeate collection limitations of available EPA-NRMRL bench-scale pervaporation equipment, the laboratory-scale VSEP (L-series VSEP) was only evaluated at $30^{\circ} \mathrm{C}$. Under the most advantageous conditions evaluated with the L-series VSEP ( $1.84 \mathrm{lpm}$, $30^{\circ} \mathrm{C}, 7 / 8 \mathrm{in}$. vibration amplitude), $k_{i}$ for $1,1,1$-TCA and PCE were observed to be $6.3 \times 10^{-5}$ and $6.9 \times$ $10^{-5} \mathrm{~m} / \mathrm{s}$, respectively. These values are larger than would have been achieved with the MTR1 module under similar conditions, although the relative difference would likely be less than $50 \%$. The non-vibration Reynolds numbers for both scales of VSEP modules were on the order of 100.

In two separate studies, we have reported VOC removal efficiencies obtained with spiral wound modules similar to those produced by MTR $[7,24]$. The VOC mass transfer coefficients observed with the 
MTR1 vibrating module approach those of the spiral wound modules. For example, at $60{ }^{\circ} \mathrm{C}, k_{i}$ for 1,1,1-TCA, toluene, and MTBE measured with the spiral wound modules were $7.2 \times 10^{-5}, 7.0 \times 10^{-5}$ and $3.8 \times 10^{-5} \mathrm{~m} / \mathrm{s}$ at $1 \mathrm{gpm}$ increasing to $1.1 \times 10^{-4}$, $1.1 \times 10^{-4}$ and $5.0 \times 10^{-5} \mathrm{~m} / \mathrm{s}$ at $2 \mathrm{gpm}$. By comparison, at $60^{\circ} \mathrm{C}$ and $1 \mathrm{in}$. vibration amplitude the MTR1 module delivered $k_{i}$ values which were 20,25 and $18 \%$ lower at $1 \mathrm{gpm}$ and 0,14 and $28 \%$ lower at $2 \mathrm{gpm}$ for 1,1,1-TCA, toluene and MTBE, respectively. Unfortunately, the highest values of $k_{i}$ obtained with the MTR1 module (at $2 \mathrm{gpm}, 1$ in. vibration amplitude, and $60^{\circ} \mathrm{C}$ ) could not be reproduced due to the development of a significant water leak in the module. At the time that the leak developed, experiments at even higher flow rates were planned to determine the extent to which flow rate affects flow distribution and process efficiency. The leak was traced to a square cord outer O-ring which shifted out of position during module fabrication and exposed an edge of the membrane. It is believed that the tape holding the membrane to the tray failed after repeated experiments at 1 in. vibration amplitude creating a pathway for water to enter the permeate region. Based on water flux and VOC removal observations, it was concluded that the module suffered a catastrophic failure rather than a gradual deterioration.

Based on this comparison of the spiral wound modules and the MTR1 module, it is apparent that the spiral wound modules could be operated in such a way as to deliver higher values of $k_{i}$ than the MTR1 module. Unfortunately, spiral wound module performance gains which are obtained by increasing feed flow rate result in higher liquid pressure drops. Since the spiral wound modules have operating pressure limits, efficiency is not infinitely adjustable via flow rate. In this respect, the VSEP module has an advantage because the open liquid flow path results in minimal pressure drops. For example, each $2 \mathrm{in.}$ diameter spiral wound module exhibited an average pressure drop of $4 \mathrm{psi}$ at $1 \mathrm{gpm}$ and $10 \mathrm{psi}$ at $2 \mathrm{gpm}$ and $60^{\circ} \mathrm{C}$ (pressure values $\pm 1 \mathrm{psi}$ ). Thus, a $10 \mathrm{~m}^{2}$ spiral wound system (a total of ten $2 \mathrm{in}$. diameter modules in series) would experience a pressure drop on the order of $40 \mathrm{psi}$ at $1 \mathrm{gpm}$ and $100 \mathrm{psi}$ at $2 \mathrm{gpm}$. Conversely, average pressure drops of 1.9 and 2.3 psi were observed with the MTR 1 VSEP module at $60^{\circ} \mathrm{C}$ at 1 and $2 \mathrm{gpm}$, respectively. The accuracy of the dial gauges employed for the MTR1 measurements was on the order of 2 psi, indicating that the differences in the readings (i.e. the pressure drop) obtained at 1 and $2 \mathrm{gpm}$ are not statistically different from each other. Further, it is clear that the pressure drop for the MTR1 VSEP module was nearly zero and, thus, significantly smaller than for the spiral wound modules especially considering that the MTR1 module contained $10 \mathrm{~m}^{2}$ of membrane.

From the analysis provided above, it should be apparent that liquid pumping utility demands are greatly reduced with the VSEP system. However, pump utility savings are more than made up for by the energy required to vibrate the VSEP module. Fortunately, the mass-spring-mass torsion system of the VSEP requires much less energy than might be expected. For example, the $15 \mathrm{in}$. VSEP system (the same as used in this work) uses a $7.5 \mathrm{hp}$ motor for vibration. Motor load ranges from $20 \%$ at $0.5 \mathrm{in}$. vibration amplitude to $40 \%$ at $1 \mathrm{in}$. amplitude. As a result, energy usage is only $1.5-3 \mathrm{hp}(1.1-2.2 \mathrm{~kW})$ and is independent of flow rate. The larger 36 and 84 in. VSEP systems are both equipped with a $20 \mathrm{hp}$ vibration motor. Energy usage is about 5 and $12 \mathrm{hp}$ at maximum amplitude for the 36 and 84 in. VSEP systems, respectively. Economies of scale are apparent since the energy per unit membrane area required to achieve a $1 \mathrm{in}$. amplitude in the largest module $\left(140 \mathrm{~m}^{2}\right)$ is approximately half that required for the small module (maximum area of $20 \mathrm{~m}^{2}$ ). Assuming a rate of US $\$ 0.1 / \mathrm{kWh}$, even the 84 in. VSEP unit would cost only US\$ 21 per day in utilities to operate at maximum vibration amplitude. Capital cost economies of scale are also highly attractive with the VSEP system because the maximum membrane area in an individual module is $140 \mathrm{~m}^{2}$ while typically less than $20 \mathrm{~m}^{2}$ for spiral wound modules.

As noted earlier, water flux for the CF1010 module was consistent with other silicone membranes. However, water flux for the MTR1 VSEP module was lower than expected. MTR1 water flux was $8.3 \pm 0.3 \times 10^{-2} \mathrm{~kg} / \mathrm{m}^{2} \mathrm{~h}$ at $40^{\circ} \mathrm{C}$ (circa 8 Torr) and $0.26 \pm 0.01 \mathrm{~kg} / \mathrm{m}^{2} \mathrm{~h}$ at $60^{\circ} \mathrm{C}$ (circa 22 Torr). These values are similar to those obtained with the spiral wound modules which contained a $20 \mu \mathrm{m}$ thick silicone layer-twice the thickness of the silicone layer in the MTR1 module. It is possible that the permeate pathway in MTR1 module was restricted, most likely 
due to compression of the Typar ${ }^{\circledR} \mathrm{T}-135$ permeate drainage cloth layers under the metal center O-ring retainer. Such a restriction would create a permeate pressure drop which would increase the VOC and water partial pressures on the permeate side of the membrane. Reduced water flux and VOC removal efficiency would result (although reduced VOC removal was not observed at higher permeate pressures with the MTR1 module). If such a limitation existed in the MTR1 module, then gains in efficiency could be achieved by redesigning the permeate flow path. Other possible, although less likely, explanations for the lower MTR1 water flux are that the silicone coating on the MTR1 membrane was thicker than believed or that the silicone used to make this membrane had a lower intrinsic water permeability than the silicone used in other MTR membranes of this type.

\section{Conclusions}

Detailed in this paper are the VOC removal characteristics of two full-scale vibrating pervaporation modules for aqueous solutions. As expected, vibration amplitude was the primary performance-controlling operating variable. Although the vibrations greatly reduced concentration polarization, VOC removal efficiency was still a function of flow rate, even at the highest vibration amplitude and with a relatively thick membrane. The results suggest that the primary effect of flow rate was on fluid distribution within the flow path rather than impacting the liquid boundary layer. Results observed during a field demonstration of the vibrating VSEP system were confirmed via experiments with surrogate aqueous surfactant solutions using the same membrane module, the CF1010 VSEP module. Subsequently, a VSEP module constructed with traditional pervaporation membrane, the MTR1 module, was evaluated. Under all conditions, the MTR1 module removed VOCs more efficiently than the CF1010 module. MTBE removal was most improved in the MTR1 module due to the reduced membrane resistance of the thinner MTR1 silicone layer. For the conditions tested, the mass transfer coefficients of VOCs in the MTR1 module were slightly lower than in spiral wound modules equipped with a similar membrane. Minimal liquid pressure drops were measured with both VSEP modules. Water fluxes for the VSEP modules were comparable to those obtained with other pervaporation modules containing silicone membranes. However, the water flux in the MTR1 module were lower than expected, possibly indicating the presence of a permeate restriction. Construction of another VSEP module equipped with MTR pervaporation membrane is currently planned. In this new module, each tray will be operated in series yielding a higher flow rate per tray. In addition, New Logic International has altered the design of the permeate pathway to reduce permeate flow resistance.

\section{Acknowledgements}

The authors wish to thank Greg Johnson and Marius Neagoe of New Logic International for VSEP engineering and fabrication services, Anurag Mairal and Hans Wijmans of Membrane Technology and Research for pervaporation membrane and for technical assistance, and Craig Patterson of IT Corporation for logistical and engineering support. The mention of trade names or commercial products does not constitute an endorsement or recommendation for use.

\section{References}

[1] R. Psaume, P. Aptel, Y. Aurelle, J.C. Mora, J.L. Bersillon, Pervaporation: importance of concentration polarization in the extraction of trace organics from water, J. Membr. Sci. 36 (1988) 373-384.

[2] C. Dotremont, S. Van den Ende, H. Vandommele, C. Vandecasteele, Concentration polarization and other boundary layer effects in the pervaporation of chlorinated hydrocarbons, Desalination 95 (1994) 91-113.

[3] X. Feng, R.Y.M. Huang, Concentration polarization in pervaporation separation processes, J. Membr. Sci. 92 (1994) 201-208.

[4] S. Bhattacharya, S.-T. Hwang, Concentration polarization, separation factor, and Peclet number in membrane processes, J. Membr. Sci. 132 (1997) 73-90.

[5] R.W. Baker, J.G. Wijmans, A.L. Athayde, R. Daniels, J.H. Ly, M. Le, The effect of concentration polarization on the separation of volatile organic compounds from water by pervaporation, J. Membr. Sci. 137 (1997) 159-172.

[6] R.W. Baker, A.L. Athayde, R. Daniels, M. Le, I. Pinnau, J.H. Ly, J.G. Wijmans, J.H. Kaschemekat, V.D. Helm, Development of Pervaporation to Recover and Reuse 
Volatile Organic Compounds from Industrial Waste Streams, DOE/AL/98769-1, 1997.

[7] L. Hitchens, L.M. Vane, F.R. Alvarez, VOC removal from water and surfactant solutions by pervaporation: a pilot study, Sep. Purification Technol. 24 (2001) 67-84.

[8] F.R. Alvarez, L.M. Vane, L. Hitchens, Demonstration of pilotscale pervaporation systems for volatile organic compound removal from a surfactant enhanced aquifer remediation fluid. I. Spiral wound membrane modules, Environ. Prog. 20 (2001) 53-63.

[9] Cross-Flow Pervaporation Technology, Zenon Environmental Inc., United States Environmental Protection Agency Report, EPA/540/R-95/511, 1998.

[10] L.M. Vane, F.R. Alvarez, E.L. Giroux, Reduction of concentration polarization in pervaporation using vibrating membrane module, J. Membr. Sci. 153 (1999) 233-241.

[11] L.M. Vane, L. Hitchens, F.R. Alvarez, E.L. Giroux, Field demonstration of pervaporation for the separation of volatile organic compounds from a surfactant-based soil remediation fluid, J. Hazard. Mater. 81 (2001) 141-166.

[12] P. Cote, C. Lipski, Mass transfer limitations in pervaporation for water and wastewater treatment, in: Proceedings of the Third International Conference of Pervaporation Processes Chemical Industries, 1988, pp. 449-462.

[13] P.J. Hickey, C.H. Gooding, Mass transfer in spiral wound pervaporation modules, J. Membr. Sci. 92 (1994) 59-74.

[14] C. Lipski, P. Cote, The use of pervaporation for the removal of organic contaminants from water, Environ. Prog. 9 (1990) 254-261.

[15] M.A. Hasegawa, D.A. Sabatini, J.H. Harwell, Liquid-liquid extraction for surfactant-contaminant separation and surfactant reuse, J. Environ. Eng. 123 (1997) 691-697.
[16] A.N. Clarke, R.D. Mutch Jr., D.J. Wilson, K.H. Oma, Design and implementation of pilot-scale surfactant washing/flushing technologies including surfactant reuse, Water Sci. Tech. 26 (1992) 127-135.

[17] K.T. Valsaraj, A. Gupta, L.J. Thibodeaux, D.P. Harrison, Partitioning of chloromethanes between aqueous and surfactant micellar phases, Water Res. 22 (1988) 1173-1183.

[18] J.-S. Jiang, L.M. Vane, S.K. Sikdar, Recovery of VOCs from surfactant solutions by pervaporation, J. Membr. Sci. 136 (1997) 233-247.

[19] M.A. Anderson, Influence of surfactants on vapor-liquid partitioning, Environ. Sci. Technol. 26 (1992) 2186-2191.

[20] L.M. Vane, E.L. Giroux, Henry's law constants and micellar partitioning of VOCs in surfactant systems, J. Chem. Eng. Data 45 (2000) 38-47.

[21] A.N. Clarke, K.H. Oma, M.M. Megehee, R.D. Mutch Jr., D.J. Wilson, Surfactant-Enhanced In-Situ Soil Remediation: Current and Future Techniques, 1994, pp. 965-987.

[22] I. Abou-Nemeh, A. Das, A. Saraf, K.K. Sirkar, A composite hollow fiber membrane-based pervaporation process for separation of VOCs from aqueous surfactant solutions, J. Membr. Sci. 158 (1999) 187-209.

[23] L.M. Vane, E.L. Giroux, F.R. Alvarez, L. Hitchens, Separation of volatile organic compounds from surfactant solutions by pervaporation, in: J.F. Scamehorn, J.H. Harwell (Eds.), Surfactant-Based Separations: Science and Technology, American Chemical Society, Washington, DC, 2000, pp. 5775.

[24] L.M. Vane, F.R. Alvarez, B. Mullins, Removal of methyl $t$-butyl ether (MTBE) from water by pervaporation: benchscale and pilot-scale evaluations, Environ. Sci. Technol. 35 (2001) 391-397. 